3 Asherson RA, Hughes GRV. Hypoadrenalism, Addison's disease and antiphospholipid antibodies. J Rheumatol 1991;18:1-4.

4 Ames DE, Asherson RA, Ayres B, Cassar J, Hughes GRV. Bilateral adrenal infarction, hypoadrenalism and splinter haemorrhages in the 'primary' antiphospholipid syndrome. $\mathrm{Br} J$ Rheumatol 1992;31:117-20.

5 Arnason JA, Graziano FM. Adrenal insufficiency in the antiphospholipid antibody syndrome. Semin Arthritis Rheum 1995;25:109-16.

6 Provenzale JM, Ortel TL, Nelson RC. Adrenal hemorrhages in patients with primary aniphospholipid syndrome: imaging findings. AJR Am J Roentgenol 1995;165:361-4.

7 Asherson RA, Cervera R. The antiphospholipid syndrome: a syndrome in evolution. Ann Rheum Dis 1992;51:147-50.

8 Hemostasis Committee of the Societe Francaise de Biologie clinique. Laboratory heterogeneity of the lupus anticoagulant; a multicenter study using different clotting assays on a panned of 78 samples. Thromb Res 1992;66:349-64.

9 Harris EN. The second international anticardiolipin standardization workshop/ the Kingston anti-phospholipid study (KAPS) group. Am J Pathol 1990;94:476-84.

\section{Echocardiographic findings in primary Sjögren's syndrome}

Primary Sjögren's syndrome (pSS) is a chronic autoimmune disease characterised by lymphocytic infiltration of the salivary and lacrimal glands. ${ }^{1}$ Similar lymphocytic infiltrates may invade visceral organs, and this results in several extraglandular manifestations. ${ }^{1}$ Among these, a clinically overt heart disease is very rare. $^{2-4}$ However, recent echocardiographic studies showed that asymptomatic cardiac involvement is frequent in pSS. Thus, Rantapää-Dahlqvist and colleagues ${ }^{5}$ reported signs of present or previous pericarditis in nine of $27(33 \%)$ pSS patients. Of the echocardiographic measurements, the right ventricular anterior wall and the left ventricular posterior wall were significantly smaller in patients with pericarditis than in those without pericardial serositis. Moreover, in the pericarditis patients, the regional fractional shortening of the left ventricle was significantly higher and the hypokinesia of the left ventricle significantly more frequent, when compared with those without pericarditis. Sclerosis of the aortic cups and a slight aortic regurgitation were seen in 11 and three patients, respectively. No patient had mitral valve prolapse or indirect signs of pulmonary hypertension. Mita et al $l^{\circ}$ evaluated 112 patients with SS, primary in 33 and secondary in 79 , by two dimensional echocardiography. They reported abnormal findings in $69(61.6 \%)$ of the total cohort and in $55.5 \%$ of the pSS patients. In this second group, pericardial effusion was seen in $21.2 \%$, thickening/calcification of the aortic valve in $10.3 \%$, decrease in the diastolic descent rate of mitral valve in $6.9 \%$, thickening/ calcification of mitral valve in $3.4 \%$, mitral regurgitation in $3.3 \%$, and mitral prolapse in $3.2 \%$. No pSS patient had pulmonary hypertension. Gyöngyösi et al examined 64 pSS patients and showed an echogenic pericardium in 21 (33\%). Pulmonary pressure was significantly higher in the patients group than in controls, probably because of interstitial lung disease. Left systolic parameters and left atrial diameter did not differ between the pSS patients and controls. On the contrary, the E:A wave ratio, the main Doppler index of left ventricular diastolic function, was abnormal in 21 of $42(50 \%)$ patients, in 17 of whom other parameters of diastolic function were significantly changed. No correlation between the left ventricular diastolic dysfunction and presence of an echogenic pericardium was found.

We evaluated 18 female patients diagnosed as suffering from pSS according to the EEC criteria $^{8}$ by $\mathrm{M}$-mode and two dimensional echocardiography. The mean age (SD) was 55.3 (7.4) years (range 46-67) and the mean disease duration (SD) was 6 (4.8) years (range 6 months-20). The control group consisted of 18 age matched healthy women. No patient or control had history of cardiovascular diseases, such as arterial hypertension or ischaemic heart disease. Echocardiography was carried out with an ATL Apogee 800 instrument and normal values of the measured parameters were taken from Feigenbaum. ${ }^{9}$ Transmitral diastolic flow velocities were recorded by pulsatile Doppler method. Moreover, the left ventricular diastolic function was evaluated according to Choong. ${ }^{10}$ Statistical analysis was performed using the Student's $t$ test and Scheffe's method for multiple comparison among means. The results show that only the deceleration of the $\mathrm{E}$ wave was significantly reduced in pSS (mean (SD)) (360 (84.02) $\mathrm{cm} / \mathrm{s}^{2}$ ) compared with controls (462 (84.25) $\left.\mathrm{cm} / \mathrm{s}^{2}\right) \quad(\mathrm{p}<0.0009)$, and remained significantly different when five subjects older than 60 years were excluded from both groups. No significant valvular disease was found in both groups. Additionally, present or previous pericarditis and pulmonary hypertension were not detected in pSS.

In conclusion, although overt heart involvement in pSS is very rare echocardiography shows an unexpectedly high frequency of cardiac manifestations, mainly pericarditis and diastolic dysfunction. These findings suggest that cardiac involvement must be included in the spectrum of extraglandular manifestations of pSS.

PAOLO MANGANELLI II Divisione Medica e Reumatologia, Azienda Ospedaliera di Parma, Italy

PAOLA BERNARDI UMBERTO TALIANI
Uzienda Ospedaliera di

III Divisione Medica, Azienda Ospedaliera di
Parma, Italy

CATERINA CAMINITI Azienda Ospedaliera di Parma, Italy

Correspondence to: Dr P Manganelli, II Divisione Medica e Reumatologia, Azienda Ospedaliera di Parma, Via Gramsci, 14, 43100 Parma, Italy.

1 Fox RI, Howell FV, Bone RC, Michelson P. Primary Sjögren's syndrome: clinical and immunopathologic features. Semin Arthritis Rheum 1984;14:77-105.

2 YiXin W. Sjögren's syndrome with myocarditis. Report of a case. Chin Med J 1981;94:45-6.

3 Tsuji M, Nakatani T, Nojiri T, et al. A case of Sjögren's syndrome with valvular diseases. Jpn Heart J 1986;27:137-43.

4 Lee LA, Pickrell MB, Reichlin M. Development of complete heart block in an adult patient with Sjögren's syndrome and anti-Ro/SS-A autoantibodies. Arthritis Rheum 1996;39: $1427-9$

5 Rantapää-Dahlqvist S, Backman C, Sandgren $\mathrm{H}$, Ostberg Y. Echocardiographic findings in patients with primary Sjögren's syndrome. Clin Rheumatol 1993;12:214-8.

6 Mita S, Akizuki S, Koido N, Ohosone Y, Suzuki A, Matsuo-Ka Y, et al. Cardiac involvement in Sjögren's syndrome detected by twodimensional ultrasonic cardiography. In: Homma M, Sugai S, Tojo T, Miyasaka N, Akizuki M, eds. Sjögren's syndrome - state

7 Gyöngyösi M, Pokorny G, Jambrik Z, Kovács L, Kovács A, Makula É, et al. Cardiac manifestaKovacs A, Makula E, et al. Cardiac manifesta-
tions in primary Sjögren's syndrome. Ann tions in primary Sjögren's
Rheum Dis 1996;55:450-4.
8 Vitali C, Bombardieri S, Moutsopoulos HM, Balestrieri G, Bencivelli W, Bernstein RM, et al. Preliminary criteria for the classification of Sjögren's syndrome. Results of a prospective concerted action supported by the European Community. Arthritis Rheum 1993;36:340-7.

9 Feigenbaum H. Echocardiography. 4th ed. Philadelphia: Lea and Febiger, 1986: 625.(Appendix B.)

10 Choong CY. Left ventricle V: diastolic function: its principles and evaluation. In: Weyman $\mathrm{AE}$, ed. Principles and practice of echocardiography. 721-80.

\section{An acute multiorgan thrombotic disorder associated with antiphospholipid antibodies; two 'catastrophic' cases}

Over the past decade the antiphospholipid syndrome (APS) was defined by the presence of antiphospholipid antibodies (aPL) and clinical manifestations including thrombosis, recurrent fetal loss, thrombocytopenia, chorea, livedo reticularis, heart valve lesions, and renal involvement. ${ }^{1}$ Asherson et al first drew attention to a catastrophic variant of APS (CAPS) that is characterised by multiple widespread vascular occlusions, leading to multiple organ failure and often death. ${ }^{2}$ We describe two non-systemic lupus erythematosus (SLE) patients with a strikingly similar clinical presentation of CAPS and emphasise the difficulties in differentiating CAPS from other thrombotic angiopathies.

\section{Case reports}

CASE REPORT ONE

A 20 year old woman presented with transient hemichorea in 1993. Computed tomography of the brain was normal. From June 1995, episodes of hemichorea reoccurred together with severe frontal headaches. In November 1995 she was admitted to our hospital with rapid deterioration of vision and behavioural changes.

Physical examination showed subcoma, blood pressure $150 / 115 \mathrm{~mm} \mathrm{Hg}$, livedo reticularis, ischaemic skin ulcerations, and a systolic cardiac murmur. Fundoscopy showed arteriolar occlusions, bleeding, and exudates.

Laboratory findings included: platelet count $47 \times 10^{9} / 1$, creatinine $176 \mu \mathrm{mol} / 1$, fibrin degradation products $1.0 \mathrm{mg} / 1$ (normal $<0.5$ ), fibrinogen $4.0 \mathrm{~g} / 1$ (normal range 2.0-4.0), haptoglobin $0.2 \mathrm{~g} / 1$ (0.3-1.8), reticulocytes $62 \%(7-30)$, positive direct Coombs test, microscopic haematuria and proteinuria (3.9 g/day). Both Lupus anticoagulant (LAC; dRVVT; IL Test LACscreen and LACconfirm, Instrumentation Laboratory, Milan, Italy)) and high titre IgG and $\operatorname{IgM}$ anticardiolipin antibodies (aCL) were present; ANA were negative. Echocardiography showed mitral regurgitation but no vegetations. Brain magnetic resonance imaging showed multiple ischaemic infarctions. A skin biopsy specimen from a livedo-reticularis lesion showed thrombotic occlusions of arterioles and venules with partial recanalisation.

Treatment consisted of high dose corticosteroids, plasma exchange, anticoagulation, cyclophosphamide (1000 mg intravenous), and platelet transfusions. After three weeks she gradually regained consciousness and renal 
function returned to normal (fig 1). Prednisone was tapered and stopped after three months; oral anticoagulation was continued. One year later she is able to walk; visual field defects and memory defects persist.

\section{CASE REPORT TWO}

A 45 year old woman was admitted to our hospital in November 1995 with acute anuric renal failure, disorientation, and dysarthric speech. Blood pressure was 180/100 mm Hg. There was livedo reticularis and ischaemic skin ulcerations on the nose. Fundoscopy showed vascular occlusions.

Her medical history disclosed recurrent fetal loss during her early twenties, deep venous thrombosis, transient hemichorea, and from March 1995 episodes with severe headaches, behavioural changes, and dysarthria. No diagnosis had been made. Fundoscopy at that time was normal.
Admission laboratory data included: haemoglobin $5.8 \mathrm{mmol} / \mathrm{l}$, platelet count $50 \times 10^{9} / 1$, schistocytes in a bloodsmear, creatinine 714 $\mu \mathrm{mol} / \mathrm{l}$, fibrin degradation products $8.0 \mathrm{mg} / \mathrm{l}$, fibrinogen $1.8 \mathrm{~g} / 1$, haptoglobin $0.7 \mathrm{~g} / 1$, reticulocytes $36 \%$, direct Coombs test positive, microscopic haematuria with red cell casts and a +++ proteinuria. LAC and aCL were strongly positive; ANA were absent. Echocardiocraphy showed severe mitral regurgitation without vegetations. Brain magnetic imaging showed multiple non-haemorrhagic infarctions.

Figure 2 shows the treatment she was given. She developed a deep venous thrombosis and massive rhabdomyolysis. Anticoagulation had to be stopped twice because of severe bleeding complications. After three weeks platelet count started to rise, but she died from intracerebral haemorrhage.

At necropsy many organs showed extensive thrombotic non-inflammatory microangio-
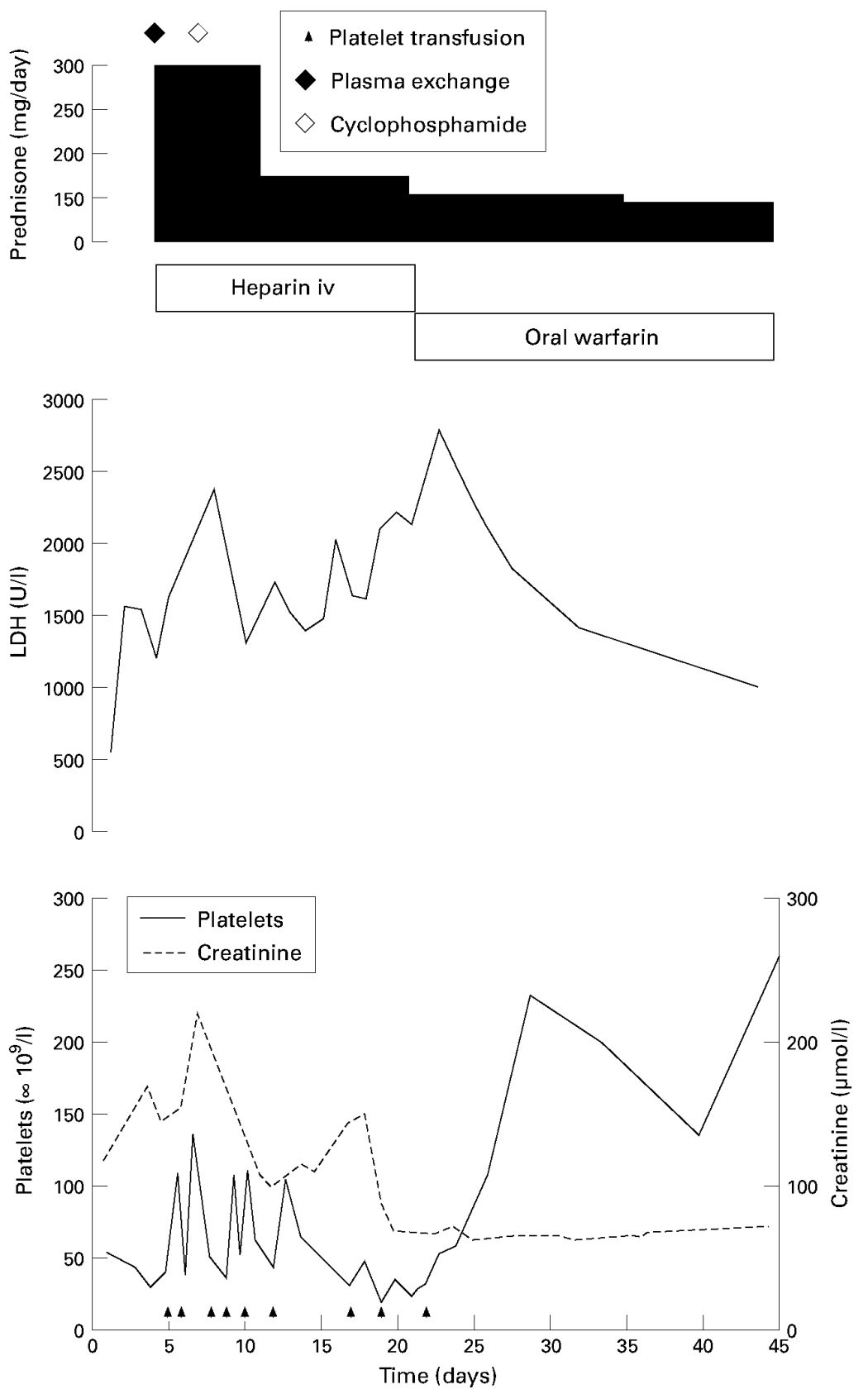

Figure 1 Course of essential laboratory data and treatment regimen of patient one.
Table 1 Laboratory results on admission

\begin{tabular}{|c|c|c|}
\hline Parameter & Patient 1 & Patient 2 \\
\hline Haemoglobin & $\downarrow$ & $\downarrow$ \\
\hline Platelets & $\downarrow$ & $\downarrow$ \\
\hline Schistocytes & Absent & Present \\
\hline Creatinine & $\uparrow$ & $\uparrow \uparrow$ \\
\hline Lactate dehydrogenase & $\uparrow$ & $\uparrow$ \\
\hline $\begin{array}{l}\text { Fibrin degradation } \\
\text { products }\end{array}$ & $\uparrow$ & $\uparrow$ \\
\hline Fibrinogen & Normal & $\downarrow$ \\
\hline Haptoglobin & $\downarrow$ & Normal \\
\hline Direct Coombs test & Positive & Positive \\
\hline Reticulocytes & $\uparrow \uparrow$ & $\uparrow$ \\
\hline $\mathrm{LAC} / \mathrm{aCL}$ & Positive & Positive \\
\hline ANA & Negative & Negative \\
\hline
\end{tabular}

pathy with both fresh and partial recanalised thrombi, leading to multiple infarctions. There was no vasculitis or glomerulonephritis.

\section{Discussion}

In 1992 Asherson introduced the descriptive adjective 'catastrophic' to APS to describe a subgroup of patients with aPL and a devastating concatenation of thrombotic complications in many organs. ${ }^{2}$

To our knowledge 31 patients with multiorgan thromboses in association with aPL have been reported ${ }^{3}$; 17 with SLE or lupus-like syndrome, ${ }^{2-6}$ one with rheumatoid arthritis, ${ }^{6}$ and 13 classified as primary APS. $^{238-12}$ Our two patients were ANA negative and did not meet sufficient ARA criteria for SLE. Their clinical presentations are compatible with APS. Both arterial and venous non-inflammatory thrombotic occlusions seem to be the common link.

Although therapeutically relevant, differentiating CAPS from thrombotic thrombocytopenic purpura, disseminated intravascular coagulation, systemic vasculitis, and malignant hypertension can be extremely difficult. It has been suggested that distinction by clinical and serological manifestations can be made. ${ }^{13}$ However, our patients illustrate the problem of overlap between these disorders (table 1). This has been confirmed by others. ${ }^{14}$ At first glance these results may seem confusing. However, the concept of a hypercoagulable state as a final common pathway of endothelial cell damage with triggering moments, not yet well defined, might contribute to a better understanding of underlying pathophysiological processes. ${ }^{13}$

Recommended treatment is controversial. It has been suggested that similar to thrombotic thrombocytopenic purpura plasma exchange with fresh frozen plasma may be beneficial in CAPS. ${ }^{2}$ We could not confirm this (figs 1 and 2). The rationale for potentially hazardous immunosuppressive treatment in case of a non-inflammatory vasculopathy remains unclear. We suggest that fundoscopy and easy obtainable biopsy specimens from skin lesions may help to demonstrate the thrombotic non-vasculitis origin of the disease and provide arguments to withhold immunosuppressive treatment. Anticoagulation brings about considerable risks of bleeding but seems to be essential.

$$
\begin{array}{r}
\text { CHRISTIAAN BOERMA } \\
\text { RONALD DERKSEN } \\
\text { Department of Rheumatology and Clinical } \\
\text { Immunology } \\
\text { BART VAN DER WIEL } \\
\text { Department of Pathology, University Hospital } \\
\text { Utrecht, the Netherlands }
\end{array}
$$

Correspondence to: $\mathrm{Dr} \mathrm{R} \mathrm{H}$ W M Derksen, Departments of Rheumatology and Clinical Immunology (F02.126), University Hospital, PO Box 85500 , 3508GA, Utrecht, the Netherlands. 


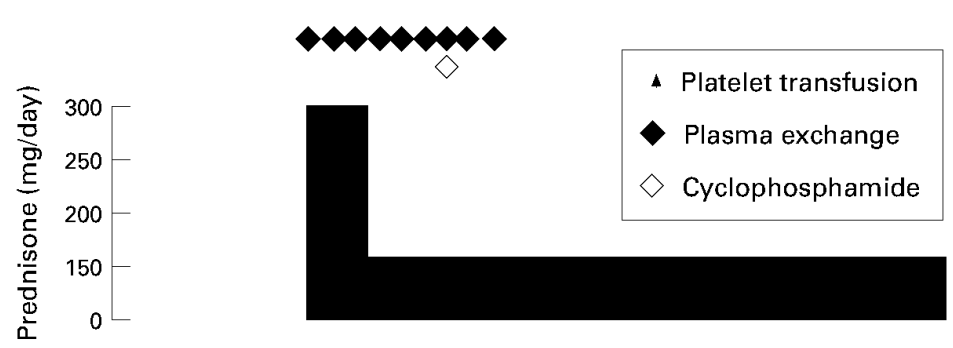

Heparin iv

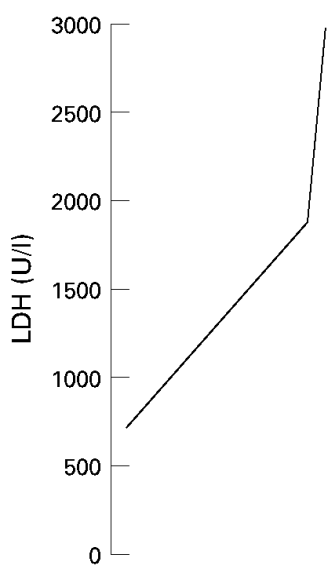

69369
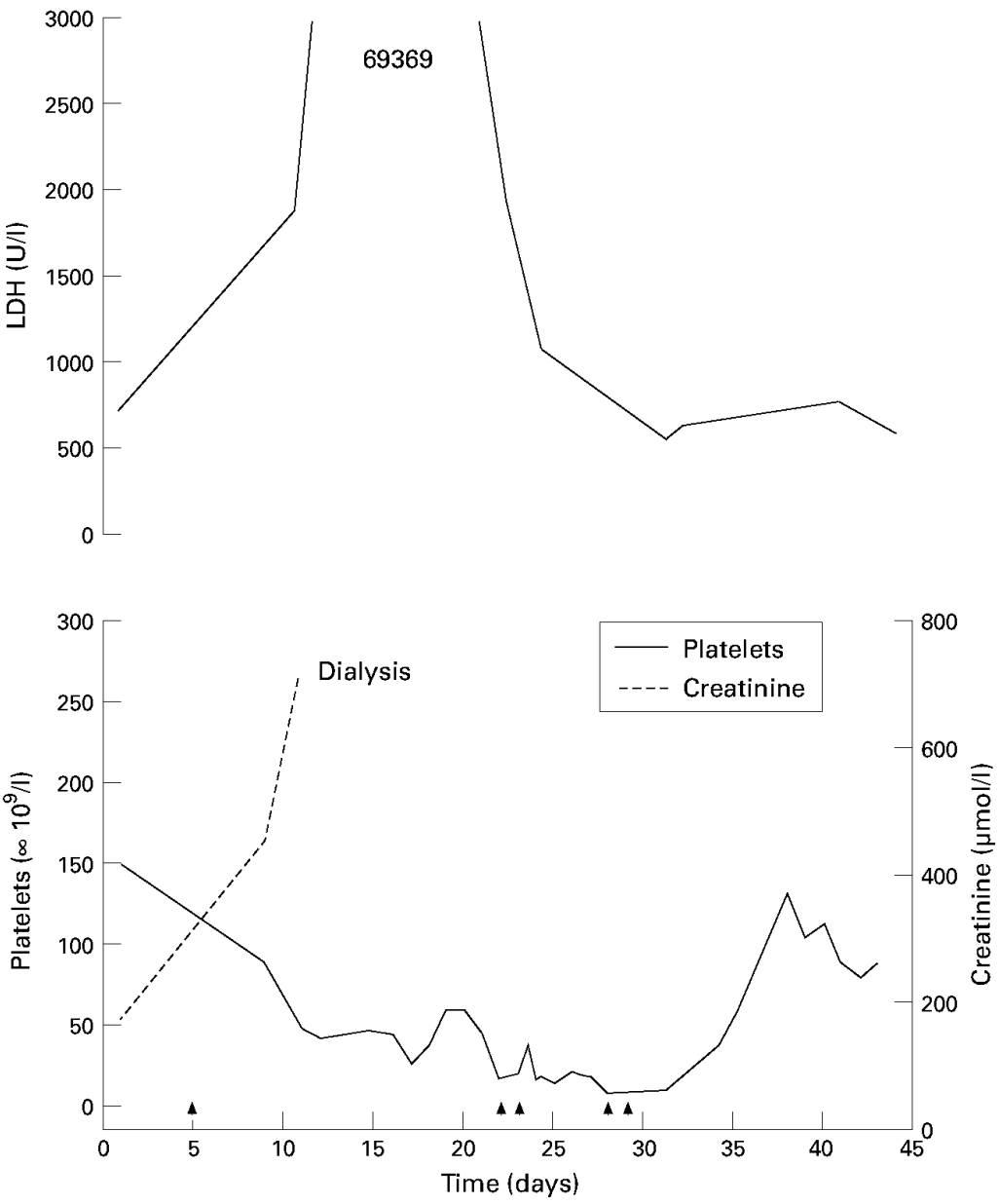

Figure 2 Course of essential laboratory data and treatment regimen of patient two.

1 Cervera R, Asherson RA, Lie JT. Clinicopathologic correlations of the antiphospholipid syndrome. Semin Arthritis Rheum 1995; 24:262-72.

2 Asherson RA. The catastrophic antiphospholipid syndrome. J Rheumatol 1992;19:508-12.

3 Asherson RA, Piette J-C. The catastrophic antiphospholipid syndrome 1996: acute multiorgan failure associated with antiphospholipid antibodies: a review of 31 patients. Lupus 1996;5:414-7.

4 Mazzucchelli R, Barbadillo C, Youssef H, Bernaldo De Quiros L, Mulero J, et al. Catastrophic antiphospholipid syndrome: a rare manifestation of the antiphospholipid antibody syndrome. Clin Exp Rheumatol 1993;11:653-7.

5 Cacoub P, Wechsler B, Piette JC, Beaufils H, Herreman G, Bletry O, et al. Malignant hypertension in antiphospholipid syndrome without tension in antiphospholipid syndrome without
overt lupus nephritis. Clin Exp Rheumatol 1993;11:479-85.
6 Peddi VR, Kant KS. Catastrophic secondary antiphospholipid syndrome with concomitant antithrombin III deficiency. J Am Soc Nephrol 1995;5:1882-7.

7 Voisin L, Derumeaux G, Borg JY, Mejiad O, Vittecoq O, Tayot J, et al. Catastrophic antiphospholipid syndrome with fatal acute course in rheumatoid disease. J Rheumatol $1995 ; 22: 1586-8$

8 Diaz-Coto JF, Barahona-Cuellar R. Catastrophic antiphospholipid syndrome. Presentation of a case. Rev Clin Esp 1995;195:29-30 9 Egan RM, Munn RK. Catastrophic antiphospholipid antibody syndrome presenting with

Table 1 The comparison of anti-HCV between the general population and patients with SLE

\begin{tabular}{llll}
\hline & Total $(n)$ & anti-HCV $(+)(n)$ & Frequency (\%) \\
\hline General population & 5257 & 77 & 1.4 \\
Patients with SLE & 38 & 1 & $2.6^{\star}$ \\
\hline
\end{tabular}

$\star \mathrm{p}>0.05$. (c100, 33c, c22) were assessed by the second generation Abbott enzyme linked immunosorbent assay (ELISA) according to manufacturer's instructions. It was estimated that the prevalence of anti-HCV antibodies (second generation ELISA) in the healthy population was $1.4 \%$ in our region. The $\chi^{2}$ test was used to perform statistical comparison. Table 1 shows the findings.

Anti-HCV was found to be positive in only one $(2.6 \%)$ patient. She was 33 years of age. multiple thromboses and sites of avascular necrosis. J Rheumatol 1194;21:2376-9.

10 Vivaldi P, Andreotti C, Mazzon C, Pedrazzoli M. A "primitive" catastrophic antiphospholipid syndrome. Haematologica 1994;79:173-6. 11 Hochfeld M, Druzin ML, Maia D, Wright J, Lambert RE, McGuire J. Pregnancy complicated by primary antiphospholipid antibody syndrome. Obstet Gynaecol 1994;83:804-5.

12 Ruffatti A, De Silvestro G, Ghirardello A, Calligaro A, Del Ross T, Thiene G, et al. A catastrophic antiphospholipid syndrome: the importance of high levels of warfarin anticoagulation. J Intern Med 1994;235:81-3.

13 Asherson RA, Cervera R, Font J. Multiorgan thrombotic disorders in systemic lupus erythematosus: A common link? Iupus 1992; 1:199-203.

14 Jain R, Chartash E, Susin M, Furie R. Systemic lupus erythematosus complicated by thrombotic microangiopathy. Semin Arthritis Rheum 1994;24:173-82.

\section{Prevalence of hepatitis C virus antibody in patients with systemic lupus erythematosus}

Systemic lupus erythematosus (SLE) is a disease of unknown aetiology characterised by impaired immune regulation and production of polyclonal autoantibodies. It is reported in the medical literature that in patients with chronic hepatitis resulting from hepatitis $\mathrm{C}$ virus (HCV) more autoantibodies such as antinuclear antibodies, anti-ds DNA, antiphospholipid antibody, antithyroglobulin antibody, rheumatoid factor, cryoglobulinaemia, and anti-GOR (an HCV induced, host derived epitope) are seen than in patients with other causes of hepatitis virus. ${ }^{1-3}$ There have also been reports on HCV associated with several immunological diseases including membranoproliferative glomerulonephritis, ${ }^{4}$ polyarteritis nodosa, ${ }^{5}$ essential mixed cryoglobulinaemia, ${ }^{6}$ Sjögren's syndrome, ${ }^{7}$ and rheumatoid arthritis. ${ }^{8}$ There are not enough data, however, on the frequency of $\mathrm{HCV}$ infection in SLE cases. Therefore, we planned a study to investigate prevalence of anti-HCV in SLE cases.

Thirty eight patients (36 female) with SLE were included in the study. Their mean (SD) age was 31 (12) years (range 8-64). Diagnosis of SLE was made according to revised criteria of the American Rheumatology Association. ${ }^{9}$ The most common clinical and laboratory findings include arthralgia (59\%), fever $(58 \%)$, cutaneous manifestations $(20 \%)$, leucopenia $(40 \%)$, lupus nephritis (65\%), antinuclear antibodies (80\%), anti-DNA (49\%), and low values of C3 and C4 $(40 \%)$.

Antibodies against $\mathrm{HCV}$ encoded antigens 